\title{
BMJ Open Temporal changes in predicted risk of type 2 diabetes in Germany: findings from the German Health Interview and Examination Surveys 1997-1999 and 2008-2011
}

\author{
Rebecca Paprott, ${ }^{1,2}$ Gert B M Mensink, ${ }^{1}$ Matthias B Schulze, ${ }^{2,3}$ Silke Thiele, ${ }^{4}$ \\ Kristin Mühlenbruch, ${ }^{2,3}$ Christa Scheidt-Nave, ${ }^{1,2}$ Christin Heidemann ${ }^{1,2}$
}

To cite: Paprott R,

Mensink GBM, Schulze MB, et al. Temporal changes in predicted risk of type 2 diabetes in Germany: findings from the German Health Interview and Examination Surveys 1997-1999 and 2008-2011. BMJ Open 2017;7:e013058. doi:10.1136/ bmjopen-2016-013058

- Prepublication history and additional material for this paper are available online. To view these files please visit the journal online (http://dx.doi. org/10.1136/bmjopen-2016013058).

Received 15 June 2016 Revised 28 February 2017 Accepted 29 March 2017

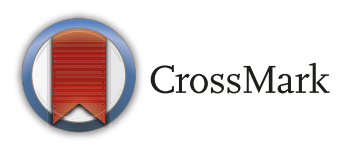

${ }^{1}$ Department of Epidemiology and Health Monitoring, Robert Koch Institute, Berlin, Germany ${ }^{2}$ German Center for Diabetes Research (DZD), Neuherberg, Germany

${ }^{3}$ Department of Molecular Epidemiology, German Institute of Human Nutrition Potsdam-

Rehbruecke, Nuthetal, Germany ${ }^{4}$ Department of Food Economics and Consumption Studies, Christian-Albrechts-University Kiel, Kiel, Germany

Correspondence to Dr Christin Heidemann; heidemannc@rki.de

\section{ABSTRACT}

Objective Over time, prevalence changes in individual diabetes risk factors have been observed for Germany and other European countries. We aimed to investigate the temporal change of a summary measure of type 2 diabetes risk in Germany.

Design Comparison of data from two cross-sectional surveys that are about 12 years apart.

Setting Two nationwide health examination surveys representative for the non-institutionalised population aged 18-79 years in Germany.

Participants The study included participants without diagnosed diabetes from the national health examination surveys in 1997-1999 $(\mathrm{n}=6457)$ and 2008-2011 $(\mathrm{n}=6095)$.

Outcome measures Predicted 5-year type 2 diabetes risk was calculated using the German Diabetes Risk Score (GDRS), which considers information on age, anthropometry, lifestyle factors, hypertension and family history of diabetes.

Results Between the two survey periods, the overall age- and sex-standardised predicted 5-year risk of type 2 diabetes decreased by $27 \%$ from $1.5 \%$ (95\% Cl 1.4\% to $1.6 \%)$ to $1.1 \%(1.0 \%$ to $1.2 \%)$. The decrease in red meat intake and waist circumference had the highest impact on the overall decrease in diabetes risk. In stratified analyses, diabetes risk decreased among both sexes and within strata of age and body mass index. Diabetes risk also decreased among highly educated persons, but remained unchanged among persons with a middle or low educational level.

Conclusions Monitoring type 2 diabetes risk by a summary measure such as the GDRS could essentially contribute to interpret the dynamics in diabetes epidemiology.

\section{INTRODUCTION}

Diabetes mellitus is a metabolic disease characterised by chronic hyperglycaemia. It may cause several long-term complications leading to disability, decreased life expectancy and increased healthcare expenditures. ${ }^{1}$ Apart from non-modifiable
Strengths and limitations of this study

- The current study is based on two consecutive, nationwide health examination surveys representative for the non-institutionalised population.

- Several sensitivity analyses confirmed the main finding of a decrease in predicted type 2 diabetes risk.

- The assessment of some components of the German Diabetes Risk Score slightly differed between both surveys.

- Despite the carefully designed sampling procedure and the application of complex weighting factors, we cannot exclude the possibility of selection bias.

risk factors such as age and family history of diabetes, the main modifiable risk factors for type 2 diabetes are overweight, a westernised diet, physical inactivity and smoking. ${ }^{2}$ In recent years, prevalence changes in several risk factors for type 2 diabetes were observed for Germany and other European countries. ${ }^{3-6}$ In Germany, for example, the prevalence of physical inactivity during leisure time and the prevalence of smoking decreased, whereas the prevalence of obesity increased during the past decade. ${ }^{36-9}$

Since these changes in risk factors differ in their direction and the strength of their influence on diabetes risk, monitoring a summary measure to estimate future diabetes risk could help to estimate net changes in diabetes risk $^{10}$ which in turn could help to understand the epidemiology of diabetes. Moreover, the monitoring of diabetes risk over time could support the evaluation of prevention programmes and enable evidence-informed policy advising. 
Therefore, the objective of the present study was to investigate the temporal change in predicted type 2 diabetes risk among adults in Germany applying the German Diabetes Risk Score (GDRS). The GDRS was originally developed based on data of the European Prospective Investigation into Cancer and Nutrition (EPIC)-Potsdam study and contains information on age, lifestyle factors, anthropometry and history of hypertension. ${ }^{11}$ Subsequently, it was extended by information on family history of diabetes. ${ }^{12}$ Recently, the most updated version of the GDRS ${ }^{13}$ has been successfully validated for predicting diabetes risk in the general German adult population. ${ }^{14}$

\section{METHODS}

\section{Study population}

The German National Health Interview and Examination Survey 1998 (GNHIES98; 1997-1999) encompasses a representative sample of the non-institutionalised population aged 18-79 years in Germany $(\mathrm{n}=7124$; response: $61 \%) .{ }^{15}$ For the German Health Interview and Examination Survey for Adults (DEGS1; 2008-2011), eligible participants of GNHIES98 were reinvited. The sample of reattendees $(n=3959$; response: 62\%) was extended by a sample of firsttime invitees $(n=4192$; response: $42 \%)$ to retain a representative cross-sectional sample of the population aged 18-79 years in Germany. ${ }^{16}$ For both surveys, a two-stage cluster sampling procedure was applied which has been described in detail previously. ${ }^{15-17}$ Both surveys were approved by the Federal Commissioner for Data Protection, and DEGS1 was approved by the ethics committee of the Charité-Universitätsmedizin Berlin (no EA2/047/08). All subjects provided written informed consent. ${ }^{16}$

For the present analyses, participants aged 18-79 years who completed both the interview and examination part (GNHIES98: $\mathrm{n}=7124$; DEGS1: $\mathrm{n}=7115$ ) were eligible. Exclusion criteria comprised diagnosed diabetes (self-reported physician-diagnosed diabetes or use of antidiabetic medication $\left.{ }^{18}(\mathrm{n}=374 ; \mathrm{n}=591)\right)$ and missing information on diabetes status $(n=25 ; n=36)$ or any GDRS component $(n=268 ; n=393)$, yielding a final sample of 6457 GNHIES98 participants and 6095 DEGS1 participants.

\section{Assessment of GDRS components}

In our survey samples, the individual components of the GDRS were assessed as described in detail elsewhere. ${ }^{14}$ In brief, information on smoking including the number of cigarettes smoked per day and regular sport activity was assessed through standardised self-administered questionnaires. ${ }^{16}$ Regular sport activity was assessed as 'no sport', '<1 hour/week', '1-2 hours/ week', '2-4 hours/week', '>4hours/week' and was converted into a quasicontinuous variable by assigning the mean time of each category (ie, 0 hours/week,
0.5 hours/week, 1.5 hours/week, 3 hours/week and 4.5 hours/week).

Standardised measurements of body height and waist circumference were performed by trained health professionals with participants wearing no shoes. A small change in the protocol relates to measurement in underwear in DEGS1 but in light clothing in GNHIES98. ${ }^{19}$

Information on history of hypertension in GNHIES98 and DEGS1 and parental history of diabetes in DEGS1 was assessed by standardised physician-administered computer-assisted interviews. ${ }^{16}$ In GNHIES98, information on parental history of diabetes was not assessed. Therefore, we assigned the observed prevalence of a history of diabetes in one parent $(24.0 \%)$ or both parents $(2.0 \%)$ from DEGS1 participants with available information to all GNHIES98 participants as a constant. The observed prevalences were calculated before the above-mentioned exclusion criteria were applied. These constants were also assigned to all DEGS1 participants with missing information on parental history of diabetes $(n=382)$ to preclude their exclusion from analysis. Information on sibling history of diabetes was neither ascertained in GNHIES98 nor in DEGS1. Therefore, we assigned the prevalence of a history of diabetes in siblings in EPIC-Potsdam $(5.0 \%)$ as a constant to all GNHIES98 and DEGS1 participants. ${ }^{12}$

In GNHIES98, a Food Frequency Questionnaire (FFQ) with seven categories of frequency was applied to assess the consumption of 'coffee with caffeine', 'whole grain bread', 'muesli, cornflakes and oatmeal' and 'meat (including poultry)'. Moreover, in the German Nutrition Survey module encompassing a subsample of 4030 GNHIES98 participants, a computer-aided personal interview was conducted by trained nutritionists to assess the usual frequencies and amounts of intake during the past 4 weeks. ${ }^{2021}$ From this subsample, we used the dietary history information stratified according to sex and age group to calculate the mean amount consumed per day for each category of the GNHIES98-FFQ for the above-mentioned foods. The obtained values were allocated to the respective categories of frequency for all GNHIES98 participants. In DEGS1, a semiquantitative FFQ was applied consisting of 11 categories of frequency and five categories of amounts. Categories of amounts were comparable between DEGS1 and EPIC-Potsdam. Consequently, we assigned the respective portion sizes as used in EPICPotsdam (ie, $150 \mathrm{~g}$ for red meat, $150 \mathrm{~mL}$ for coffee and $50 \mathrm{~g}$ for whole grain bread and muesli) to estimate the average intake in grams per day. ${ }^{12}$

\section{Calculation of GDRS points and predicted 5-year type 2 diabetes risk}

In this study, the overall GDRS points were calculated according to the following previously published algorithm, which includes the multiplication of each GDRS 
component by a weight that corresponds to the derived $\beta$ coefficient from a Cox regression model ${ }^{13}$ :

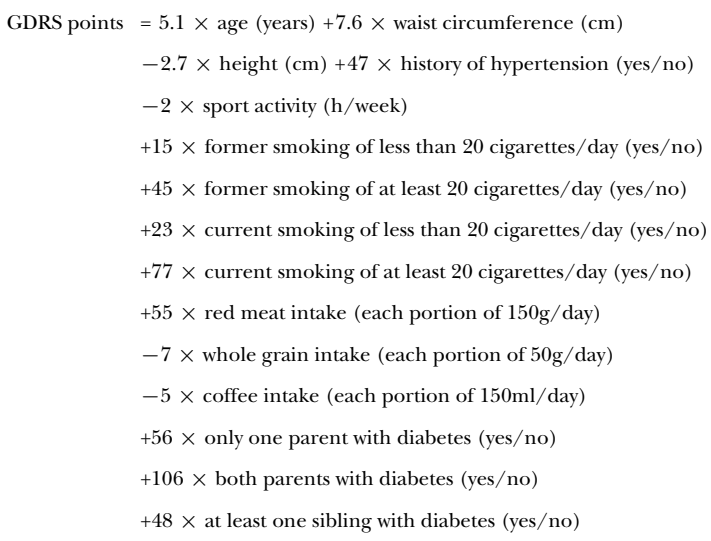

The corresponding predicted 5-year type 2 diabetes risk was calculated by inserting the obtained GDRS points into the following formula:

$$
P_{(5 \text { years })}=1-0.99061^{\exp }((\text { GDRS points }-474.17096591) / 100)
$$

The derivation of this formula in EPIC-Potsdam has been described before. ${ }^{12}$ In brief, the equation is based on three components: the baseline survival function for 5 years estimated in EPIC-Potsdam, the individual GDRS points calculated in the present study and the mean GDRS points estimated in EPIC-Potsdam.

\section{Statistical analysis}

For statistical analyses, means (95\% CI) and frequencies (95\% CI) were calculated with SAS V.9.4 (SAS Institute, Cary, North Carolina, USA). To account for the complex clustered sample design of the survey samples, we applied SAS survey procedures as well as a weighting factor to account for differences between the survey sample and the general population as previously described. ${ }^{16}{ }^{18}$ For comparisons between both surveys, data were weighted to the age and sex structure of the German population as of 31 December 2010. Several sensitivity analyses were conducted. For stratified analyses, stratification variables were used as previously defined. ${ }^{18}$

\section{Results}

Between 1997-1999 and 2008-2011, age- and sex-standardised predicted diabetes risk decreased from $1.5 \%$ to $1.1 \%$ among German adults (table 1). This development was largely explained by an increased proportion of adults with a low diabetes risk $(<0.2 \%)$ and a decreased proportion with higher diabetes risk, that is, in the groups $1.2 \%-2.0 \%$ and $3.3 \%-24.4 \%$ as shown in figure 1 . In several sensitivity analyses, findings remained essentially the same (table 2).

Several GDRS components, namely waist circumference, height, sport activity, current smoking of at least 20 cigarettes/day, coffee consumption and red meat intake, changed in a favourable way, whereas history of hypertension, former and current smoking of less than 20 cigarettes/day and whole grain intake changed in an unfavourable way (table 1). When further considering each component's individual weighting factor for predicting diabetes risk, changes in red meat intake (equivalent to -13.4 GDRS points) and waist circumference $(-11.6$ points) had the highest impact on the overall decrease of predicted diabetes risk, while changes in current smoking of at least 20 cigarettes/day (-4.2 points), height ( -3.4 points) and coffee consumption (-3.1 points) rather moderately decreased predicted diabetes risk. In contrast, the increase in history of hypertension ( +4.1 points) moderately elevated predicted diabetes risk. Changes in the remaining observed GDRS components, that is, sport activity, former smoking of less than 20 cigarettes / day, former smoking of at least 20 cigarettes/day, current smoking of less than 20 cigarettes/day and whole grain intake, had a rather negligible influence $(<2.0$ points) (table 1$)$.

At both survey periods, predicted diabetes risk was higher in men compared with women, in low educated adults compared with those with a middle or high educational level and in central-eastern compared with southern Germany. Diabetes risk consistently increased with increasing age and body mass index (BMI) (table 2). Between the two survey periods, predicted diabetes risk decreased in both sexes and within defined strata of age, BMI and region. Predicted diabetes risk decreased among highly educated adults, while it remained at a relatively low level among those with middle education and at a relatively high level among those with low education (table 2).

\section{DISCUSSION}

Overall predicted 5-year type 2 diabetes risk decreased among adults in Germany between 1997-1999 and 2008-2011. This finding was confirmed in several sensitivity analyses and also observed in analyses stratified by sex, age, BMI and region. However, temporal changes in predicted diabetes risk differed according to educational level.

Decreases in the mean intake of red meat and in mean waist circumference were identified as having the highest impact on the observed decline in predicted 5-year diabetes risk between 1997-1999 and 2008-2011. When interpreting the dietary changes, particularly the decrease in red meat intake, differences between the assessment methods of both surveys need to be considered. However, comparing overall meat intake in the German Nutrition Survey (1997-1999) ${ }^{22}$ with meat and meat product intake in the German National Nutrition Survey II (20052006), ${ }^{23}$ both applying the same assessment method (Diet Interview Software for Health Examination Studies (DISHES)), also showed a decrease. This is further in line with the marginal decrease in red meat intake found for Western Europe in another study. ${ }^{5}$ Besides, in a sensitivity analysis applying a constant for red meat intake, the decrease in predicted diabetes risk remained statistically significant (table 2). With respect to abdominal obesity, 


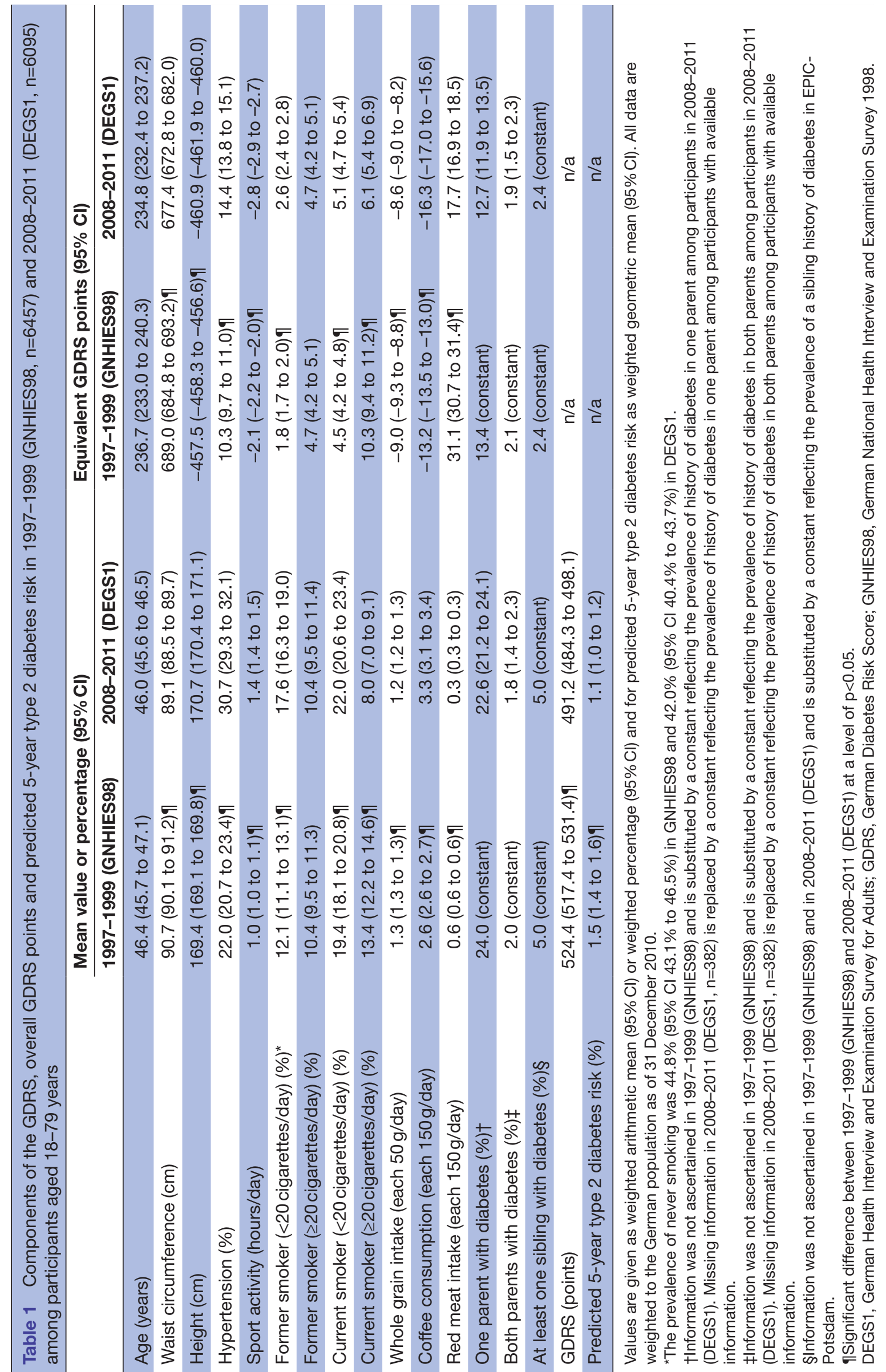




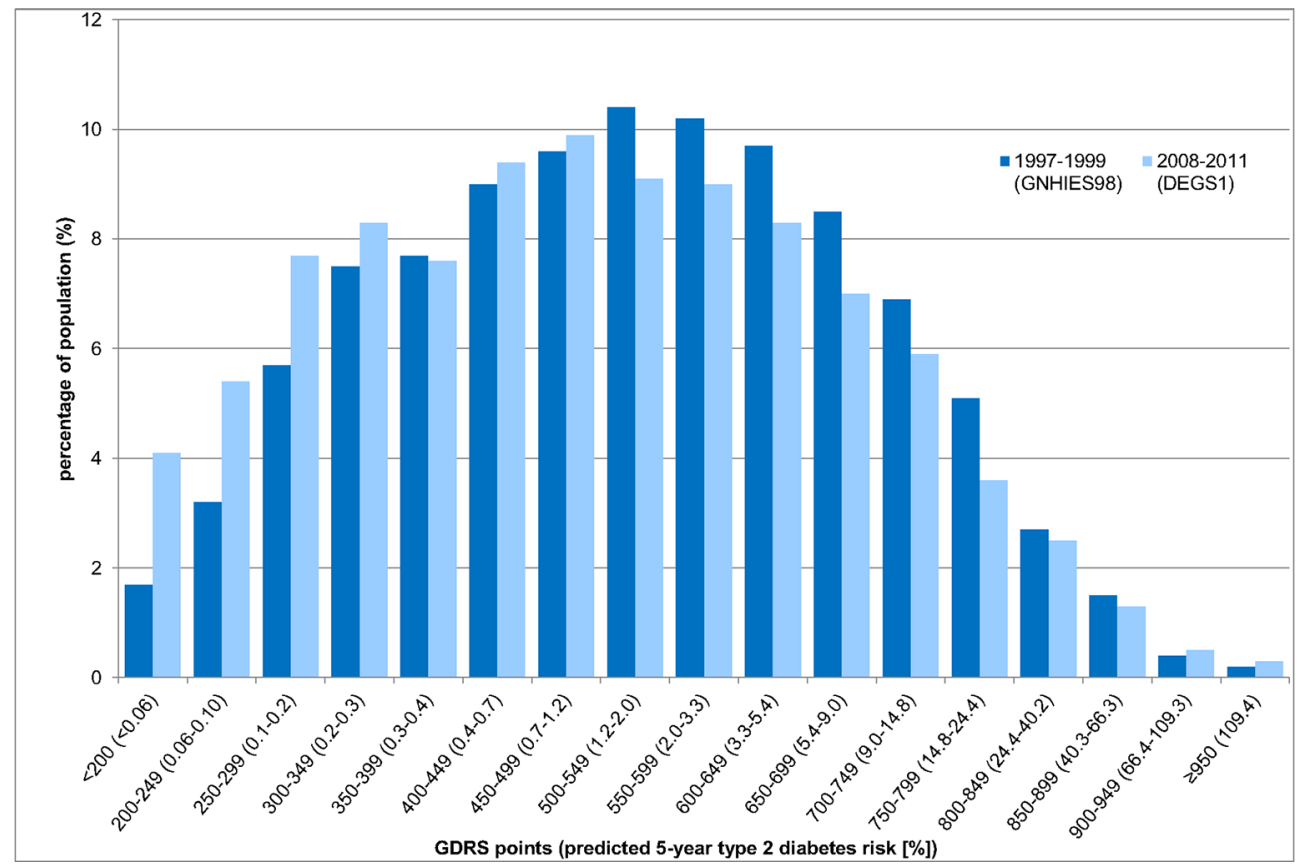

Figure 1 Distribution of GDRS points (predicted 5-year type 2 diabetes risk (\%)) in 1997-1999 (GNHIES98, n=6457) and 2008-2011 (DEGS1, n=6095) among participants aged 18-79 years. All data are weighted to the German population as of 31 December 2010. DEGS1, German Health Interview and Examination Survey for Adults; GDRS, German Diabetes Risk Score; GNHIES98, German National Health Interview and Examination Survey 1998.

the age-standardised prevalence marginally decreased among men (waist circumference $\geq 94 \mathrm{~cm}$ ) in a regionally confined German study, whereas it slightly increased among women (waist circumference $\geq 80 \mathrm{~cm}$ ). ${ }^{24}$ We cannot exclude that the overall decrease in mean waist circumference observed in the current study was partly based on differences in measurement methods between both surveys. Still, in a sensitivity analysis applying a constant for waist circumference for both survey periods the decrease in predicted diabetes risk remained statistically significant (table 2 ).

Further, the decrease in current smoking of at least 20 cigarettes/day and the increase in hypertension diagnosis had a moderate, though in case of hypertension opposing influence on the change in predicted diabetes risk. A decreased prevalence of current heavy smoking was also seen in another German study, ${ }^{25}$ which is probably largely attributable to measures targeted at decreasing the smoking prevalence, for example, increased tobacco taxes and smoking bans. ${ }^{25}{ }^{26}$ The increased prevalence of a self-reported history of hypertension found in the present study, however, was difficult to compare to the findings of other studies as the definition of hypertension usually further includes use of antihypertensive agents and hypertensive blood pressure. When applying such an extended definition of hypertension, the prevalence of hypertension no longer differed between the two survey periods as previously shown. ${ }^{27}$ Nevertheless, the overall change in predicted diabetes risk remained statistically significant (table 1).

The decrease in predicted diabetes risk observed over time in the overall population was also seen in all examined strata of sex, age, BMI and residential region, but in terms of educational level was only evident among highly educated adults. An additional analysis revealed that the latter was mainly due to differences in the temporal development of waist circumference, which significantly decreased only among highly educated adults (data not shown).

The favourable changes in some diabetes risk factors and the resulting decrease in predicted diabetes risk observed in the current study are in line with the previously observed decreased prevalence of pre-diabetes and undiagnosed diabetes among German adults. ${ }^{18}$ As previously suggested, the increased prevalence of diagnosed diabetes in Germany during the same period of time might, therefore, be largely attributable to a somewhat earlier diabetes diagnosis, that is, a shift from undiagnosed to diagnosed diabetes and improvements in diabetes care potentially leading to a longer life span in persons with diabetes. ${ }^{18} 28$

In other countries, temporal changes in predicted risk for coronary heart or cardiovascular disease based on risk factors partly overlapping with those of the GDRS have been examined. Similar to the current finding, 10-year risk of coronary heart disease significantly declined between 1999 and 2010 in the $\mathrm{USA}^{10}$ and 10-year risk of cardiovascular disease significantly declined between 2007 and 2012 in France. ${ }^{29}$

Limitations of the current study include that the assessment of some GDRS components differed between both surveys. In addition, we had no information on parental history of diabetes in the earlier survey and no information on sibling history of diabetes at 
Table 2 Predicted 5-year type 2 diabetes risk (\%, 95\% Cl) in 1997-1999 (GNHIES98, $\mathrm{n}=6457)$ and 2008-2011 (DEGS1, $\mathrm{n}=6095$ ) according to sensitivity and stratified analyses among participants aged 18-79 years

\begin{tabular}{lll}
$1997-1999$ & $2008-2011$ & p Value \\
(GNHIES98) & (DEGS1) & for trend \\
\hline
\end{tabular}

\section{Sensitivity analyses}

\begin{tabular}{|c|c|c|c|}
\hline $\begin{array}{l}\text { Exclusion of participants with hemoglobin A1c ( } \mathrm{HbA} 1 \mathrm{c}) \text { levels }=48 \mathrm{mmol} / \mathrm{mol} \\
(6.5 \%)^{\star}\end{array}$ & 1.4 (1.3 to 1.5$)$ & 1.0 (1.0 to 1.1$)$ & $<0.01$ \\
\hline $\begin{array}{l}\text { History of hypertension defined as use of antihypertensive agents and self- } \\
\text { reported physician diagnosis or systolic blood pressure }=140 \mathrm{~mm} \mathrm{Hg} \text { or } \\
\text { diastolic blood pressure }=90 \mathrm{~mm} \mathrm{Hg} \dagger\end{array}$ & 1.5 (1.4 to 1.7$)$ & 1.1 (1.0 to 1.2$)$ & $<0.01$ \\
\hline $\begin{array}{l}\text { Mean whole grain intake in DEGS1 assigned as a constant to all GNHIES98 } \\
\text { participants }\end{array}$ & 1.5 (1.4 to 1.6$)$ & 1.1 (1.0 to 1.2$)$ & $<0.01$ \\
\hline $\begin{array}{l}\text { Mean red meat intake in DEGS1 assigned as a constant to all GNHIES98 } \\
\text { participants }\end{array}$ & 1.3 (1.2 to 1.4$)$ & 1.1 (1.0 to 1.2 ) & $<0.01$ \\
\hline $\begin{array}{l}\text { Mean coffee intake in DEGS1 assigned as a constant to all GNHIES98 } \\
\text { participants }\end{array}$ & 1.5 (1.4 to 1.6$)$ & 1.1 (1.0 to 1.2$)$ & $<0.01$ \\
\hline $\begin{array}{l}\text { Mean waist circumference in DEGS1 assigned as a constant to all GNHIES98 } \\
\text { participants }\end{array}$ & 1.4 (1.3 to 1.4$)$ & 1.1 (1.1 to 1.1$)$ & $<0.01$ \\
\hline
\end{tabular}

\section{Stratified analyses}

\begin{tabular}{|c|c|c|c|}
\hline \multicolumn{4}{|l|}{ Sex } \\
\hline Women & 1.1 (1.0 to 1.2 ) & 0.8 (0.7 to 0.9$)$ & $<0.01$ \\
\hline Men & 2.2 (2.0 to 2.3 ) & 1.5 (1.3 to 1.6$)$ & $<0.01$ \\
\hline \multicolumn{4}{|l|}{ Age } \\
\hline $18-44$ years & 0.5 (0.4 to 0.5$)$ & 0.3 (0.3 to 0.3 ) & $<0.01$ \\
\hline 45-64 years & 2.9 (2.7 to 3.1$)$ & 2.2 (2.1 to 2.4 ) & $<0.01$ \\
\hline $65-79$ years & 9.9 (9.1 to 10.7$)$ & 7.7 (7.2 to 8.3$)$ & $<0.01$ \\
\hline \multicolumn{4}{|l|}{ Educationł } \\
\hline Low & 2.7 (2.5 to 2.9 ) & 2.5 (2.2 to 2.7$)$ & 0.12 \\
\hline Middle & 0.7 (0.7 to 0.8$)$ & 0.7 (0.6 to 0.8$)$ & 0.29 \\
\hline High & 1.3 (1.1 to 1.4$)$ & 0.8 (0.7 to 1.0$)$ & $<0.01$ \\
\hline \multicolumn{4}{|l|}{ BMI $\left(\mathrm{kg} / \mathrm{m}^{2}\right) \S$} \\
\hline$<25.0$ & 0.4 (0.4 to 0.5$)$ & 0.3 (0.3 to 0.3 ) & $<0.01$ \\
\hline 25.0-29.9 & 2.4 (2.2 to 2.5$)$ & 1.7 (1.6 to 1.8$)$ & $<0.01$ \\
\hline$=30.0$ & 7.2 (6.7 to 7.8$)$ & 6.4 (5.8 to 7.0$)$ & 0.03 \\
\hline \multicolumn{4}{|l|}{ Region } \\
\hline North-East & 1.6 (1.2 to 2.1$)$ & 1.0 (0.9 to 1.3$)$ & $<0.01$ \\
\hline Central-East & 1.7 (1.5 to 2.0 ) & 1.4 (1.2 to 1.6$)$ & 0.02 \\
\hline North-West & 1.4 (1.2 to 1.7$)$ & 1.0 (0.8 to 1.3$)$ & $<0.01$ \\
\hline Central-West & 1.6 (1.4 to 1.8$)$ & 1.1 (1.0 to 1.2 ) & $<0.01$ \\
\hline South & 1.4 (1.3 to 1.6$)$ & $1.0(0.9$ to 1.1$)$ & $<0.01$ \\
\hline
\end{tabular}

All data are weighted to the German population as of 31 December 2010.

*Exclusion of 240 participants in 1997-1999 (GNHIES98) and 128 participants in 2008-2011 (DEGS1).

†Information was missing for 15 participants in 1997-1999 (GNHIES98) and 22 participants in 2008-2011 (DEGS1).

fInformation was missing for 18 participants in 1997-1999 (GNHIES98) and 11 participants in 2008-2011 (DEGS1).

§Information was missing for nine participants in 2008-2011 (DEGS1).

BMI, body mass index; DEGS1, German Health Interview and Examination Survey for Adults; GNHIES98, German National Health Interview and Examination Survey 1998.

all. However, from a genetic point of view, we would not expect a considerable change in this component during the relatively short period of about 12 years.
Finally, despite the application of complex weighting factors, we cannot exclude the possibility of selection bias. $^{18}$ 
In summary, between 1997-1999 and 2008-2011, overall predicted risk for future type 2 diabetes decreased among adults in Germany. Public health monitoring of diabetes risk factors and of overall diabetes risk in the general population could essentially contribute to understand the complex dynamics of diabetes epidemiology and to guide health policy decisions for diabetes prevention.

Acknowledgements We would like to thank Thorsten Heuer (Max Rubner-Institut) for his valuable feedback on interpretation of dietary changes among the German population, Anja Schienkiewitz (Robert Koch Institute) for her support in interpreting temporal changes in waist circumference and Hannelore K Neuhauser (Robert Koch Institute) for her support in interpreting temporal changes in the prevalence of hypertension.

Contributors $\mathrm{CH}$ and CSN conceptualised the study. RP analysed the data and drafted the manuscript. CH supported statistical analyses. GBMM, MBS, ST, $\mathrm{KM}, \mathrm{CSN}$ and $\mathrm{CH}$ contributed to interpretation of data and critically revised the manuscript for important intellectual content. All authors read and approved the final version of the manuscript.

Funding The survey GNHIES98 and the primary part of DEGS1 were funded by the German Federal Ministry of Health. This study was supported by research grants from the German Federal Ministry of Health (FKZ: GE20130320) and from the German Center for Diabetes Research (DZD) funded by the German Federal Ministry of Education and Research (FKZ: HMGU2015Z1).

\section{Competing interests None declared.}

Ethics approval Both surveys were approved by the Federal Commissioner for Data Protection, and DEGS1 was approved by the ethics committee of the CharitéUniversitätsmedizin Berlin (no EA2/047/08).

Provenance and peer review Not commissioned; externally peer reviewed. Data sharing statement No additional data available.

Open Access This is an Open Access article distributed in accordance with the Creative Commons Attribution Non Commercial (CC BY-NC 4.0) license, which permits others to distribute, remix, adapt, build upon this work non-commercially, and license their derivative works on different terms, provided the original work is properly cited and the use is non-commercial. See: http://creativecommons.org/ licenses/by-nc/4.0/

(c) Article author(s) (or their employer(s) unless otherwise stated in the text of the article) 2017. All rights reserved. No commercial use is permitted unless otherwise expressly granted.

\section{REFERENCES}

1. Jaacks LM, Siegel KR, Gujral UP, et al. Type 2 diabetes: a 21st century epidemic. Best Pract Res Clin Endocrinol Metab 2016;30:331-43.

2. Chen L, Magliano DJ, Zimmet PZ. The worldwide epidemiology of type 2 diabetes mellitus--present and future perspectives. Nat Rev Endocrinol 2011;8:228-36.

3. Völzke H, Ittermann T, Schmidt CO, et al. Prevalence trends in lifestyle-related risk factors. Dtsch Arzteb/ Int 2015;112:185-92.

4. Plass D, Vos T, Hornberg C, et al. Trends in disease burden in Germany: results, implications and limitations of the global burden of disease study. Dtsch Arztebl Int 2014;111:629-38.

5. Micha R, Khatibzadeh S, Shi P, et al. Global, regional and national consumption of Major food groups in 1990 and 2010: a systematic analysis including 266 country-specific nutrition surveys worldwide. BMJ Open 2015;5:e008705.

6. Finger JD, Busch MA, Du Y, et al. Time Trends in Cardiometabolic Risk factors in adults. Dtsch Arztebl Int 2016;113:712-9.

7. Lampert T, von der Lippe E, Müters S. (Prevalence of smoking in the adult population of Germany: results of the German Health Interview and Examination Survey for adults (DEGS1)). Bundesgesundheitsblatt Gesundheitsforschung Gesundheitsschutz 2013;56:802-8.

8. Krug S, Jordan S, Mensink GBM, et al. [Physical activity: results of the German Health Interview and Examination Survey for adults (DEGS1)]. Bundesgesundheitsblatt Gesundheitsforschung Gesundheitsschutz 2013;56(5-6):765-71.

9. Mensink GBM, Schienkiewitz A, Haftenberger M, et al. Overweight and obesity in Germany: results of the German Health Interview and Examination Survey for adults (DEGS1). Bundesgesundheitsblatt Gesundheitsforschung Gesundheitsschutz 2013;56:786-94.

10. Ford ES. Trends in predicted 10-year risk of coronary heart disease and cardiovascular disease among U.S. adults from 1999 to 2010. J Am Coll Cardiol 2013;61:2249-52.

11. Schulze MB, Hoffmann $\mathrm{K}$, Boeing $\mathrm{H}$, et al. An accurate risk score based on anthropometric, dietary, and lifestyle factors to predict the development of type 2 diabetes. Diabetes Care 2007;30:510-5.

12. Mühlenbruch $\mathrm{K}$, Ludwig T, Jeppesen $\mathrm{C}$, et al. Update of the German Diabetes risk score and External validation in the German MONICA/ KORA study. Diabetes Res Clin Pract 2014;104:459-66.

13. Mühlenbruch $\mathrm{K}$, Joost $\mathrm{H}-\mathrm{G}$, Boeing $\mathrm{H}$, et al. Risk prediction for type 2 diabetes in the german population with the updated German Diabetes risk score (GDRS). Ernährungs Umschau 2014:90-3 https:// www.ernaehrungs-umschau.de/fileadmin/Ernaehrungs-Umschau/ pdfs/pdf_2014/06_14/EU06_14_90_Muehlenbruch_englisch.pdf.

14. Paprott R, Mühlenbruch K, Mensink GBM, et al. Validation of the German Diabetes Risk Score among the general adult population: findings from the German Health Interview and Examination Surveys. BMJ Open Diabetes Res Care 2016;4:e000280.

15. Thefeld W, Stolzenberg H, Bellach B-M. German National Health Interview and Examination survey: response, composition of participants, and analysis of non-respondents. Das Gesundheitswesen 1999;61:57-61.

16. Scheidt-Nave C, Kamtsiuris P, Gößwald A, et al. German health interview and examination survey for adults (DEGS) - design, objectives and implementation of the first data collection wave. BMC Public Health 2012;12:730.

17. Kamtsiuris P, Lange M, Hoffmann R, et al. [The first wave of the German Health Interview and Examination Survey for Adults (DEGS1): sample design, response, weighting and representativeness]. Bundesgesundheitsblatt Gesundheitsforschung Gesundheitsschutz 2013;56:620-30.

18. Heidemann $\mathrm{C}$, Du Y, Paprott R, et al. Temporal changes in the prevalence of diagnosed diabetes, undiagnosed diabetes and prediabetes: findings from the German Health Interview and Examination surveys in 1997-1999 and 2008-2011. Diabet Med 2016;33:1406-14.

19. Schienkiewitz A, Mensink GBM, Scheidt-Nave C. Comorbidity of overweight and obesity in a nationally representative sample of german adults aged 18-79 years. BMC Public Health 2012;12:658.

20. Heidemann C, Scheidt-Nave C, Richter A, et al. Dietary patterns are associated with cardiometabolic risk factors in a representative study population of german adults. Br J Nutr 2011;106:1253-62.

21. Mensink GBM, Haftenberger M, Thamm M. Validity of DISHES 98, a computerised dietary history interview: energy and macronutrient intake. Eur J Clin Nutr 2001;55:409-17.

22. Mensink GBM, Beitz R. Food and nutrient intake in East and West Germany, 8 years after the reunification--the German Nutrition Survey 1998. Eur J Clin Nutr 2004;58:1000-10.

23. Heuer T, Krems C, Moon K, et al. Food consumption of adults in Germany: results of the German National Nutrition Survey II based on diet history interviews. Br J Nutr 2015;113:1603-14.

24. Hoffmann W, Bahr J, Weitmann K, et al. Not just the Demographic Change--the impact of trends in risk factor prevalences on the prediction of Future cases of Myocardial infarction. PLoS One 2015;10:e0131256.

25. Lampert T. Smoking. Robert Koch Koch Institute Berlin, GBE kompakt 2(4)2011: www.rki.de/gbe-kompak accepted 24 May 2011

26. Kohler S, Minkner P. Smoke-free laws and direct democracy initiatives on smoking bans in Germany: a systematic review and quantitative assessment. Int J Environ Res Public Health 2014;11:685-700.

27. Neuhauser HK, Adler C, Schaffrath Rosario A, et al. Hypertension prevalence, awareness, treatment and control in Germany 1998 and 2008-11. J Hum Hypertens 2015;29.

28. Du Y, Heidemann C, Schaffrath Rosario A, et al. Changes in diabetes care indicators: findings from German National Health Interview and Examination surveys 1997-1999 and 2008-2011. BMJ Open Diabetes Res Care 2015;3:e000135.

29. Karam C, Beauchet A, Czernichow S, et al. Trends in Cardiovascular Disease risk factor prevalence and estimated 10-Year Cardiovascular risk scores in a large untreated french Urban Population: the CARVAR 92 Study. PLoS One 2015;10:e0124817. 